\title{
Horizontal transfer of vanA between probiotic Enterococcus faecium and Enterococcus faecalis in fermented soybean meal and in digestive tract of growing pigs
}

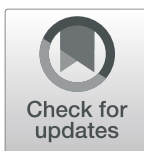

Ning $\mathrm{Li}^{1,2}$, Haitao Yu ${ }^{1,2}$, Hongbin Liu ${ }^{1,2}$, Yuming Wang ${ }^{1,2}$, Junyan Zhou ${ }^{1,2}, \mathrm{Xi} \mathrm{Ma}^{1,2}$, Zheng Wang ${ }^{3}$, Chengtao Sun $^{3}$ and Shiyan Qiao ${ }^{1,2^{*}}$

\begin{abstract}
Background: The aim of this study was to investigate the intergeneric transfer of vancomycin resistance gene vanA between probiotic enterococci in the fermentation progress of soybean meal and in the digestive tract of growing pigs. One vanA genotype vancomycin resistant $E$. faecium strain, Efm4, and one chloramphenicol-resistant E. faecalis strain, Efs2, were isolated from twenty-nine probiotic basis feed material / additive samples. For in vitro conjugation, Efm4 and Efs2 were used as starter to ferment soybean meal. For in vivo conjugation, thirty growing pigs were randomly assigned to five groups $(n=6)$, treated with a basic diet, or supplemented with $10 \%$ fermented soybean meal, $1 \%$ Efm4, $5 \%$ Efs2 or a combination of 1\% Efm4 + 5\% Efs 2 for $7 \mathrm{~d}$, respectively. Fecal samples of pigs in each group were collected daily for the isolation and dynamic analysis of Efm4, Efs2 and transconjugants. The sequence types (STs) of Efm4, Efs2 and transconjugants were analyzed by multilocus sequence typing (MLST). The vanA harboring plasmid in Efm4 and transconjugants was analyzed by S1-pulsed field gel electrophoresis (PFGE) and further verified by multiple alignments.
\end{abstract}

Results: The results showed that, in FSBM, transconjugants were detected $1 \mathrm{~h}$ after the fermentation, with a conjugation frequency of $\sim 10^{-3}$ transconjugants / recipient. Transconjugants proliferated with Efm4 and Efs 2 in the first $8 \mathrm{~h}$ and maintained steadily for $10 \mathrm{~d}$ till the end of the experiment. Additionally, in vivo experiment showed that transcojugants were recovered in one of six pigs in both FSBM and Efm4 + Efs2 groups, with conjugation frequency of $\sim 10^{-5}$ and $\sim 10^{-4}$, respectively. MLST revealed the ST of Efm4, Efs2 and transconjugants was ST1014, ST69 and ST69, respectively. S1-PFGE confirmed the existence of the vanA-harboring, 142,988-bp plasmid, which was also a multi-drug resistant plasmid containing Tn1546-like transposon.

Conclusions: The findings revealed the potential safety hazard existing in the commercial probiotic enterococci in China, because the horizontal transfer from farm to fork could potentially pose a safety risk to the public.

Keywords: Chloramphenicol, Digestive tract, Enterococci, Fermented soybean meal, Growing pigs, Probiotics, Transconjugants, vanA, Vancomycin

\footnotetext{
* Correspondence: qiaoshiyan@cau.edu.cn

${ }^{1}$ State Key Laboratory of Animal Nutrition, College of Animal Science and

Technology, China Agricultural University, Beijing 10093, China

${ }^{2}$ Beijing Key Laboratory of Bio-feed Additives, China Agricultural University,

Beijing 10093, China

Full list of author information is available at the end of the article
}

(c) The Author(s). 2019 Open Access This article is distributed under the terms of the Creative Commons Attribution 4.0 International License (https://creativecommons.org/licenses/by/4.0/), which permits unrestricted use, distribution, and reproduction in any medium, provided you give appropriate credit to the original author(s) and the source, provide a link to the Creative Commons license, and indicate if changes were made. The Creative Commons Public Domain Dedication waiver (https://creativecommons.org/publicdomain/zero/1.0/) applies to the data made available in this article, unless otherwise stated. 


\section{Background}

Enterococci species are widely distributed in the environment and enable to colonize in the gastrointestinal tract in humans and most animals [1]. For decades, some enterococci strains like Enterococcus faecium and Enterococcus faecalis are used as probiotics in human and farm animals as a kind of lactic acid bacteria [2]. Previous studies have proven that enterococci can maintain a balance among the intestinal flora [3], promote the absorption of nutrients [46] and improve the host immunity [7-9]. In spite of those probiotic properties, however, enterococci have also been known as one of the multiresistant pathogen, ranking among the leading causes of hospital-acquired infections worldwide [10-12].

Vancomycin therapy is one of the most efficient treatments for enterococci infections. While the emergence and rapid spread of vancomycin-resistant enterococci (VRE) represents a particular challenge [13, 14], as there are few remaining therapeutic options for infections caused by VRE $[15,16]$. Glycopeptide resistance genes van is proven to be the major vancomycin resistant mechanism known in the enterococci. Within all the nine van gene types [17], vanA is the most frequently indentified one among enterococci isolates from clinical settings $[18,19]$. The ability of enterococci to acquire and exchange plasmids and mobile genetic elements that carry antimicrobial resistance gens (like vanA) has contributed to their role as multiresistant pathogens within both human and animals.

The spread of VRE as well as vanA is not restricted only clinically but they appear also in the community and natural environment as well as animal sectors. For instance, the emergence of VRE in food animal in Europe is proven to have a high association with the use of avoparcin, a glycopeptide antibiotic as growth promoting agent in animal feed [20]. Avoparcin was never approved as a feed additive in China, and worldwide reports on VRE in the livestock industry is limited.

Recently, growing attention has been focused on the worrisome situation of VRE in hospitals or community care centers, which might be traced back to the consumed food, such as yogurt and pork, and eventually to the diet that farm animals intake [21]. Therefore, the aim of this study was to determine the VRE strains in commercial available probiotic enterococci in Beijing, China. Moreover, to assess the potential security issue of these bacteria as an accumulator of antibiotic resistance genes (ARGs), horizontal dissemination of $v a n A$ between $E$. faecium and $E$. faecalis in fermented soybean meal (FSBM) and the digestive tract of growing pigs were also analyzed.

\section{Materials and methods}

\section{Bacterial isolates}

Enterococci based FSBM and silage corn samples, as well as microbial feed additive samples were purchased in swine farms and local husbandry and veterinary stations in Beijing, China, during June to December, 2016. For FSBM and silage corn samples, enterococci enrichment was performed by adding $25 \mathrm{~g}$ sample into $225 \mathrm{~mL}$ of Buffered Peptone Water (Beijing Land Bridge, China), vortexed, and then incubated at $37^{\circ} \mathrm{C}$ for $24 \mathrm{~h}$. Then 1 $\mathrm{mL}$ of the enrichment was added into $9 \mathrm{~mL}$ Bile Esculin Azide (BEA; Beijing Land Bridge, China) broth and then incubated $37^{\circ} \mathrm{C}$ for $24 \mathrm{~h}$. The changing color of BEA broth from transparent dark brown to opaque black was a sign of the existence of enterococci. A loop of enrichment was streaked on BEA agar plate, incubated $37^{\circ} \mathrm{C}$ for $24 \mathrm{~h}$. For feed additive samples, $1 \mathrm{~g}$ or $1 \mathrm{~mL}$ of the sample was dissolved in $9 \mathrm{~mL}$ normal saline, then a loop of the solution was streaked on BEA agar plate, incubated $37^{\circ} \mathrm{C}$ for $24 \mathrm{~h}$.

The identification of suspected strains were performed by VITEK 2 Compact Automatic Bacterial Identification and Drug Sensitivity Analysis System (bioMerieux, France) using specific Gram-positive bacteria identification cards (bioMerieux, France), followed by further confirmation of $16 \mathrm{~S}$ rDNA-based polymerase chain reaction (PCR) screen using universal primers 27-F and 1,492-R, and specific primers for E. faecium and E. faecalis (Additional file 1: Table S1).

\section{Antimicrobial susceptibility tests}

Isolates confirmed as E. faecium or E. faecalis were subjected to antimicrobial susceptibility testing to determine their resistance to twenty common antibiotics of nine categories (Additional file 1: Table S2) in accordance with the Clinical and Laboratory Standards Institute (CLSI) [22]. Each isolate was inoculated into $1 \mathrm{~mL}$ of sterilized normal saline by picking 3 to 5 colonies using cotton swab from an overnight culture on BHI agar to visually match a McFarland turbidity standard of 0.5 . The bacteria liquid was evenly coated onto the surface of un-supplemented Mueller-Hinton (Oxoid, UK) agar plates using cotton swab. Each plate was pasted with five different antimicrobial disks (Beijing Tiantan, China), and then incubated at $37^{\circ} \mathrm{C}$ for $24 \mathrm{~h}$. The diameter of inhibition zones was measured to the nearest millimeter and interpreted according to the CLSI standards and previous studies [22, 23]. The E. faecalis reference strain ATCC 29212 was used as the quality control.

\section{Choice of donor and recipient strains}

The only VRE strain, E. faecium strain, Efm4, isolated from a FSBM sample, resistant to vancomycin but susceptible to chloramphenicol, was chosen as donor strain. While another $E$. faecalis strain, $\mathrm{E} f \mathrm{~s} 2$, isolated from a microbial feed additive sample, with opposite vancomycin and chloramphenicol resistant phenotype to $\mathrm{E} f m 4$, was chosen as recipient strain. The genomic DNA of E $f m 4$ 
and $\mathrm{E} f s 2$ were extracted using Wizard ${ }^{\bullet}$ Genomic DNA Purification Kit (Promega, USA) according to manufacturer's protocol and further evaluated by PCR for the detection of $v a n$ and $c h l$ genes. (Additional file 1: Table S1).

Amplified PCR products were purified using Wizard ${ }^{\circ}$ SV Gel and PCR Clean-Up System (Promega, USA). Cleaned fragments were submitted to Sangon Biotech (Beijing, China) and sequenced from both the forward and reverse stands. The sequence was then analyzed using BLAST.

Freeze-dried powder of $\mathrm{E} f m 4$ and $\mathrm{E} f \mathrm{~s} 2$ were produced by National Feed Engineering Technology Research Center (Beijing, China), with initial bacteria counts $10^{10} \mathrm{CFU} / \mathrm{g}$, respectively, then stored at $-20^{\circ} \mathrm{C}$. Before use, the bacterial activity would be detected by measuring bacterial colony-forming ability after incubation for $24 \mathrm{~h}$ at $37^{\circ} \mathrm{C}$ on BHI agar plates.

\section{In vitro conjugation: soybean meal fermentation and sample collection}

Fresh bacteria liquid cultures of $\mathrm{E} f m 4$ and $\mathrm{E} f s 2$ were produced by overnight incubation in $\mathrm{BHI}$ broth at $37^{\circ} \mathrm{C}$, respectively, and sub-cultured before use. The initial concentration was adjusted to $\sim 10^{8} \mathrm{CFU} / \mathrm{mL}$ for both $\mathrm{E} f m 4$ and $\mathrm{E} f s 2$. FSBM was conducted in aseptic fermentation bags $(5 \mathrm{~L}$, provided by Ministry of Agricultural Feed Industry Centre, Beijing, China) using the following ingredients: sterilized soybean meal (SBM), 500 g; glucose, $20 \mathrm{~g}$; sterilized $\mathrm{dd}_{2} \mathrm{O}, 435 \mathrm{~mL}$; yeast, $5 \mathrm{~g}$; bacteria liquid, $50 \mathrm{~mL}$, with the volume ratio was 1:5 (v/v, Efm4 / $\mathrm{E} f \mathrm{~s} 2)[24,25]$. Two control groups with the same ingredients supplemented with $50 \mathrm{~mL}$ Efm4 liquid or $50 \mathrm{~mL}$ $\mathrm{E} f$ s2 liquid, respectively, were set.

All fermentation ingredients except $\mathrm{E} f m 4$ were pre-confirmed to be negative for vanA. BHI agar plates containing either $128 \mathrm{mg} / \mathrm{L}$ vancomycin or 64 $\mathrm{mg} / \mathrm{L}$ chloramphenicol were used for detection of $\mathrm{E} f m 4$ and $\mathrm{E} f s 2$, respectively. BHI agar plates supplemented with vancomycin and chloramphenicol were used for the detection of transconjugants. Five replicates were maintained for each treatment. E fm 4 , E $f s 2$ and transconjugants were counted through serial plating on selective BHI agar plates at $0,1,2,4,6,8,12$, and $24 \mathrm{~h}$, and then daily from day 2 to day 10 .

On each selective plate, five clones were randomly selected, cultured, identified by species assessment as described above. Putative transconjugants obtained on double resistant selective plates were further confirmed by PCR amplification on the detection of van and chl genes [26, 27].

The conjugant frequency was calculated using the equation described by Liu et al. [28]:
$($ Conjugation $)$ frequency $=\frac{\text { Clones of Transconjugants }(\mathrm{CFU} / \text { plate })}{\text { Clones of Recipients }(\mathrm{CFU} / \text { plate })}$

\section{In vivo conjugation: animals, feeding and sample collection}

All procedures used in these experiments were conducted in accordance with the Chinese Guidelines for Animal Welfare and were approved by the China Agricultural University Institutional Animal Care and Use Committee (Beijing, China) [29]. The pig cages, pigpens and feeding appliances were pre-disinfected, then confirmed the absence of enterococci as well as van and chl genes using methods described previously [30].

A total of thirty barrows (Duroc $\times$ Landrace $\times$ Yorkshire) at the age of $60 \mathrm{~d}$, with initial body weight of $15.38 \pm 2.8 \mathrm{~kg}$ were individually housed and provided with a non-medicated corn-soybean meal basal diet and sterilized water ad libitum for $10 \mathrm{~d}$. Fresh fecal samples were collected daily to confirm the absence VRE and vanA. After acclimatization, pigs were randomly assigned to one control group $(n=6)$, fed with the same basal diet previously described; and four treatment groups $(n=6)$, fed with basal diet supplemented with $10 \% \mathrm{FSBM}, 1 \% \mathrm{E} f \mathrm{~m} 4,5 \% \mathrm{E} f \mathrm{~s} 2$ or a combination of $1 \%$ $\mathrm{E} f m 4+5 \% \mathrm{E} f s 2$ for $7 \mathrm{~d}$, respectively.

The estimation of FSBM consumption was about $5 \mathrm{~kg} /$ $\mathrm{d}$, so 5 bags of FSBM were performed daily, from $-1 \mathrm{~d}$ to $6 \mathrm{~d}$ of the experiment as described above. The fermentation process lasted for $2 \mathrm{~d}$. At this time point, the bacteria concentrate of $\mathrm{E} f m 4$ and $\mathrm{E} f s 2$ was both $\sim 10^{9}$ CFU/g FSBM. Then $5 \mathrm{~kg}$ fresh FSBM were uniformly dispersed into $45 \mathrm{~kg}$ basal diet to feed FSBM group barrows. Meanwhile, the initial bacteria concentrate of $\mathrm{E} f m 4$ in $\mathrm{E} f m 4$ group and $\mathrm{E} f m 4+\mathrm{E} f s 2$ group was $\sim 1.0 \times$ $10^{8} \mathrm{CFU} / \mathrm{g}$ feed, and the initial bacteria concentrate of $\mathrm{E} f s 2$ in $\mathrm{E} f s 2$ group and $\mathrm{E} f m 4+\mathrm{E} f s 2$ group was $\sim 5.0 \times$ $10^{8} \mathrm{CFU} / \mathrm{g}$ feed, respectively.

Fresh rectal feces sample of each pig was collected once every $24 \mathrm{~h}$ for serial plating and counting of Efm4, $\mathrm{E} f s 2$, and transconjugants using selective BHI agar plates. Donor, recipient and transconjugant strains on selective plates and then resistant genes were identified as described above.

\section{Multilocus sequence typing}

To investigate the genetic heterogeneity of the donor, recipient and transconjugants, the MLST analysis was performed. 7 housekeeping genes were amplified using the primers and protocol specified by MLST website (https://pubmlst.org/efaecium/ and https://pubmlst.org/ efaecalis/), respectively. Allele and sequence types (STs) assignments were made at the publicly accessible MLST database described above [2, 31]. 


\section{S1-PFGE and southern hybridization}

S1-PFGE was performed as described previously [2]. Overnight incubated cells of Efm4, E $f s 2$ and transconjugants were embedded in InCert Agarose (Lonza, USA), respectively, followed by digestion with $\mathrm{S} 1$ nuclease (TaKaRa, Japan). The DNA restriction fragment were separated in $1 \%$ SeaKem Gold ${ }^{\circ}$ Agarose (Lonza, USA) using a pulse gel electrophoresis apparatus (Bio-Rad, USA). Genomic DNA of Salmonella serovar Braenderup strain H9812, digested with XbaI (TaKaRa, Japan), was used as a molecular standard.

Southern hybridization was performed on the S1-PFGE gel using DIG High Prime DNA Labeling and Detection Starter Kit II (Roche, Germany) with digoxinlabeled DNA probes specific for $v a n A$, followed by manufacturer's protocol.

\section{Plasmid sequencing}

The whole genome of Efm4 including vanA-harboring plasmid was sequenced using the Pacific Biosciences RS II (Pacific Biosciences, Menlo Park, CA, USA) sequencing platform. De novo assemblies of Pacbio Reads were performed by SMRT Analysis pipeline v2.3.0 in conjunction with RS_HGAP_Assembly. Three protocols and additional assemblies were performed by minimus 2 from the AMOS package [32]. The open reading frames (ORFs) were identified and annotated with the prodigal.

The vanA-carrying plasmids from transconjugants obtained from FSBM and $\mathrm{E} f m 4+\mathrm{E} f s 2$ group were partially sequenced $(\sim 13,000 \mathrm{bp})$ to verify their transfer into $\mathrm{E} f s 2$. By targeting the regions adjacent $v a n A$, primers (Additional file 2: Supplemental data 1) were designed based on the sequence of vanA-carrying plasmid in Efm4. Multiple alignment of acquire sequence was conducted using SnapGene (Version 4.2.6) against the sequence of vanA-carrying plasmid Efm4.

\section{Results}

\section{Antimicrobial susceptibility}

Among twenty-nine enterococci isolates, two strains $(6.90 \%, 2 / 29)$ were susceptible to all the twenty antibiotics tested; the remaining strains $(93.10 \%, 27 / 29)$ showing resistance to at least one antibiotic (Table 1). An $E$. faecium strain, Efm4, exhibited a high MIC to vancomycin $(>1,024 \mu \mathrm{g} / \mathrm{mL})$ harboring $v a n A$, while an E. faecalis strain, $\mathrm{E} f \mathrm{~s} 2$, resistant to chloramphenicol $(128 \mu \mathrm{g} /$ $\mathrm{mL}$ ) carrying catA1 on genome were selected as donor and recipient strains (Table 2).

\section{In vitro conjugation}

During the fermentation process, the donor strain Efm4 and the recipient strain $\mathrm{E} f s 2$ both grew well and had similar growth kinetics. Concentrations of $\mathrm{E} f m 4$ reached a maximum of $1.25 \times 10^{9} \mathrm{CFU} / \mathrm{g}$ FSBM at hour 10, with the concentrations of $\mathrm{E} f \mathrm{~s} 2$ reached a maximum of $6.0 \times$ $10^{8} \mathrm{CFU} / \mathrm{g}$ FSBM as well (Fig. 1). Transconjugants were detected at the first detection point of fermentation (1 h), with the cell count at $0.94 \times 10^{5} \mathrm{CFU} / \mathrm{g} \mathrm{FSBM}$, and the conjugation frequency being $1.2 \times 10^{-3}\left(0.94 \times 10^{5}\right.$ CFU/g FSBM / $7.8 \times 10^{7}$ CFU/g FSBM, transconjugants/ $\mathrm{E} f s 2$ ). The number of transconjugants increased continuously and then peaked at day 3 , at $5.8 \times 10^{6} \mathrm{CFU} / \mathrm{g}$ FSBM. Moreover, the transconjugants remained consistently at $\sim 10^{6} \mathrm{CFU} / \mathrm{g}$ FSBM during day 1 (from hour 6) to day 10 (Fig. 1).

\section{In vivo conjugation}

No pigs were colonized by vancomycin or chloramphenicol-resistant enterococci prior to the study (day-10 to -1 , data not shown). Besides, during the test period, no VRE strain was detected in the fecal samples collected from the control group fed with basil diet.

The donor, recipient, and transconjugants exhibited similar growth kinetics, indicating that these two strains could stably reside the digestive tract of growing pigs, and therefore there was no growth defect that could have affected the results (Fig. $2 a$ and b). In the fecal samples obtained from $\mathrm{E} f m 4+\mathrm{E} f s 2$ group, the concentration of $\mathrm{E} f m 4$ and $\mathrm{E} f s 2$ reached a maximum of $6.44 \times$ $10^{7} \mathrm{CFU} / \mathrm{g}$ fecal and $9.28 \times 10^{7} \mathrm{CFU} / \mathrm{g}$ fecal at day 4 , respectively (Fig. 2a). Similarly, the concentrations of Efm4 and $\mathrm{E} f s 2$ peaked at $4.88 \times 10^{7} \mathrm{CFU} / \mathrm{g}$ and $7.28 \times 10^{7}$ $\mathrm{CFU} / \mathrm{g}$ on day 3 and day 5 in the FSBM group, respectively (Fig. 2b). Notably, transconjugants were observed in both two groups, although only positively detected in one pig of six for each group. In $\mathrm{E} f m 4+\mathrm{E} f s 2$ group, the conjugation frequency reached to $1.97 \times 10^{-4}$ and $6.25 \times$ $10^{-4}$ at day 6 and day 7 (Fig. 2c, Table 3), respectively. In contrast, the transconjugant was more frequently occurred, with a conjugation frequency of $9.4 \times 10^{-5}$, $4.60 \times 10^{-4}, 2.75 \times 10^{-5}, 5.0 \times 10^{-5}$ and $9.4 \times 10^{-5}$, from day 3 to day 7 , respectively (Fig. 2b, Table 3 ).

The presence vanA and catA1 in transconjugants was confirmed by further PCR bothly in vitro and in vivo experiments.

\section{Molecular typing of probiotic enterococci isolates}

The MLST analysis identified that the ST of Efm4, Efs 2 and transconjugants was ST1014, ST69 and ST69, respectively (Table 1 ).

\section{S1-PFGE and southern hybridization}

S1-PFGE analysis exhibited one visible plasmid bands $(\sim 140 \mathrm{~kb})$ in the donor strain $\mathrm{E} f m 4$ and another bands $(\sim 60 \mathrm{~kb})$ in the recipient strain $\mathrm{E} f s 2$. It could be observed clearly that the transconjugants harbored two visible plasmids from both $\mathrm{E} f m 4$ and $\mathrm{E} f s 2$ (Fig. 3). 
Table 1 Antimicrobial susceptibilities and sequence types of enterococci isolated from feed/feed additives

\begin{tabular}{|c|c|c|c|c|c|c|c|c|c|c|c|c|c|c|c|c|c|c|c|c|c|c|}
\hline \multirow[t]{2}{*}{ Strain } & \multirow[t]{2}{*}{ Origin } & \multicolumn{20}{|c|}{ Antibiotics } & \multirow[t]{2}{*}{ ST } \\
\hline & & $\overline{V A}$ & $\mathrm{TCL}$ & RA & $C$ & AM & PIP & $C Z$ & $P$ & MPN & AMX & OFL & CIP & GTF & GM & $\mathrm{TE}$ & MNO & $E$ & $\mathrm{KIA}$ & $\mathrm{FT}$ & $\overline{F U}$ & \\
\hline Efm1 & FSBM & 1 & 1 & 1 & 1 & 1 & 1 & $\mathrm{R}$ & 1 & 1 & 1 & 1 & 1 & 1 & 1 & 1 & 1 & 1 & 1 & 1 & $R$ & ST94 \\
\hline Efm2 & FSBM & 1 & 1 & 1 & 1 & 1 & 1 & $\backslash$ & $\backslash$ & 1 & 1 & 1 & 1 & 1 & 1 & 1 & 1 & 1 & $\backslash$ & 1 & 1 & ST40 \\
\hline Efm3 & FSBM & 1 & 1 & 1 & 1 & 1 & 1 & 1 & 1 & 1 & 1 & 1 & 1 & 1 & 1 & 1 & 1 & 1 & 1 & 1 & 1 & ST296 \\
\hline Efm4 & FSBM & $\mathrm{R}$ & $\mathrm{R}$ & 1 & 1 & $\mathrm{R}$ & $\mathrm{R}$ & $\mathrm{R}$ & R & $\mathrm{R}$ & $\mathrm{R}$ & $\mathrm{R}$ & $\mathrm{R}$ & $\mathrm{R}$ & $\mathrm{R}$ & 1 & 1 & R & R & 1 & $\mathrm{R}$ & ST1014 \\
\hline Efm5 & FSBM & 1 & 1 & I & 1 & 1 & 1 & 1 & 1 & 1 & 1 & 1 & 1 & 1 & 1 & 1 & 1 & I & 1 & 1 & R & ST 296 \\
\hline Efm6 & FSBM & 1 & 1 & 1 & 1 & 1 & 1 & $R$ & 1 & 1 & 1 & 1 & 1 & 1 & 1 & 1 & 1 & । & 1 & 1 & $\mathrm{R}$ & ST 94 \\
\hline Efm7 & FSBM & 1 & 1 & 1 & 1 & 1 & 1 & 1 & 1 & 1 & 1 & 1 & 1 & 1 & 1 & 1 & 1 & I & 1 & 1 & R & ST 6 \\
\hline Efm8 & FSBM & 1 & 1 & I & 1 & 1 & 1 & 1 & 1 & 1 & 1 & 1 & 1 & 1 & 1 & 1 & 1 & 1 & 1 & 1 & $\mathrm{R}$ & ST 5 \\
\hline Efm9 & FSBM & 1 & 1 & 1 & 1 & 1 & 1 & 1 & 1 & 1 & 1 & 1 & 1 & 1 & 1 & 1 & 1 & 1 & 1 & 1 & R & ST 60 \\
\hline Efm 10 & FSBM & 1 & 1 & 1 & 1 & 1 & 1 & $\mathrm{R}$ & $\backslash$ & 1 & 1 & 1 & 1 & 1 & 1 & 1 & 1 & 1 & 1 & 1 & R & ST 6 \\
\hline Efm11 & Silage corn & 1 & 1 & 1 & 1 & 1 & 1 & $\mathrm{R}$ & 1 & $\mathrm{R}$ & 1 & 1 & 1 & 1 & 1 & 1 & 1 & I & 1 & 1 & R & ST 812 \\
\hline Efm12 & Silage corn & 1 & 1 & I & 1 & 1 & 1 & 1 & 1 & 1 & 1 & 1 & 1 & 1 & 1 & 1 & 1 & 1 & 1 & 1 & R & ST 5 \\
\hline Efm13 & Silage corn & 1 & 1 & I & 1 & 1 & 1 & $\backslash$ & 1 & 1 & 1 & 1 & 1 & 1 & 1 & 1 & 1 & I & 1 & 1 & $\mathrm{R}$ & ST 5 \\
\hline Efm14 & Silage corn & 1 & 1 & I & 1 & 1 & 1 & 1 & 1 & 1 & 1 & 1 & 1 & 1 & 1 & 1 & 1 & I & 1 & 1 & R & ST 178 \\
\hline Efm15 & Silage corn & 1 & 1 & 1 & 1 & 1 & 1 & 1 & 1 & 1 & 1 & 1 & 1 & 1 & 1 & 1 & 1 & 1 & 1 & 1 & $\mathrm{R}$ & ST 160 \\
\hline Efm16 & Silage corn & 1 & 1 & I & 1 & 1 & 1 & 1 & 1 & 1 & 1 & 1 & 1 & 1 & 1 & 1 & 1 & $\mathrm{R}$ & $\mathrm{R}$ & 1 & $\mathrm{R}$ & ST 726 \\
\hline Efm17 & Feed additive & 1 & 1 & 1 & 1 & 1 & 1 & $\mathrm{R}$ & 1 & 1 & 1 & 1 & 1 & 1 & 1 & 1 & 1 & । & 1 & 1 & $\mathrm{R}$ & ST812 \\
\hline Efm18 & Feed additive & 1 & 1 & I & 1 & 1 & 1 & $\mathrm{R}$ & 1 & 1 & 1 & 1 & 1 & 1 & 1 & 1 & 1 & । & 1 & 1 & $\mathrm{R}$ & ST 5 \\
\hline Efm19 & Feed additive & 1 & 1 & । & 1 & 1 & 1 & 1 & 1 & 1 & 1 & 1 & 1 & 1 & 1 & 1 & 1 & । & 1 & 1 & $\mathrm{R}$ & ST 5 \\
\hline Efm20 & Feed additive & 1 & 1 & 1 & 1 & 1 & 1 & 1 & 1 & 1 & 1 & 1 & 1 & 1 & 1 & 1 & 1 & 1 & 1 & 1 & R & ST 5 \\
\hline Efm21 & Feed additive & 1 & 1 & । & 1 & 1 & 1 & 1 & 1 & 1 & 1 & 1 & 1 & 1 & 1 & 1 & 1 & । & 1 & 1 & $\mathrm{R}$ & ST 361 \\
\hline Efm22 & Feed additive & 1 & 1 & $\mathrm{R}$ & 1 & 1 & 1 & 1 & 1 & 1 & 1 & 1 & 1 & 1 & 1 & 1 & 1 & 1 & 1 & 1 & $\mathrm{R}$ & ST 21 \\
\hline Efm23 & Feed additive & 1 & 1 & I & 1 & 1 & 1 & 1 & 1 & 1 & 1 & 1 & 1 & 1 & 1 & 1 & 1 & 1 & 1 & 1 & $\mathrm{R}$ & ST 21 \\
\hline Efm24 & Feed additive & 1 & 1 & 1 & 1 & 1 & 1 & 1 & 1 & । & 1 & 1 & 1 & 1 & 1 & 1 & 1 & 1 & 1 & 1 & $\mathrm{R}$ & ST 695 \\
\hline Efm25 & Feed additive & 1 & 1 & 1 & 1 & 1 & 1 & I & 1 & 1 & 1 & 1 & 1 & 1 & 1 & 1 & 1 & । & 1 & 1 & R & ST 24 \\
\hline Efm26 & Feed additive & 1 & 1 & 1 & 1 & 1 & 1 & 1 & 1 & 1 & 1 & 1 & 1 & 1 & 1 & 1 & 1 & I & 1 & 1 & $\mathrm{R}$ & ST 24 \\
\hline Efm27 & Feed additive & 1 & 1 & I & 1 & 1 & 1 & 1 & 1 & 1 & 1 & 1 & 1 & 1 & 1 & 1 & 1 & 1 & 1 & 1 & $\mathrm{R}$ & ST 21 \\
\hline Efs1 & Feed additive & 1 & 1 & 1 & 1 & 1 & 1 & I & 1 & 1 & 1 & 1 & 1 & 1 & 1 & 1 & 1 & I & 1 & 1 & R & ST 69 \\
\hline Efs2 & Feed additive & 1 & 1 & 1 & $\mathrm{R}$ & 1 & 1 & 1 & $\backslash$ & 1 & 1 & $\mathrm{R}$ & $\mathrm{R}$ & I & $\mathrm{R}$ & $\mathrm{R}$ & 1 & $\mathrm{R}$ & $\mathrm{R}$ & $\backslash$ & 1 & ST 69 \\
\hline
\end{tabular}

Efm, E. faecium isolates;

Efs, E. faecalis isolates;

1, susceptible;

R, resistant;

I, intermediate;

ST, sequence type;

VA, Vacomycin; TCL, Teicoplanin; RA, Rifampicin; C, Chloramphenicol; AM, Ampicillin; PIP, Piperacillin; CZ, Cefamedin; P, Penicillin; MPN, Meropenem; AMX, Amoxicillin; OFL, Ofloxacin; CIP, Ciprofloxacin; GTF, Gatifloxacin; GM, Gentamicin; TE, Tetracycline; MNO,

Minocycline; E, Erythromycin; Gl, Kitasamycin; FT, Nitrofurantoin; FU, Furazolidone

Southern hybridization confirmed that $v a n A$ hybridized on the visible plasmid of Efm4 with a size of $\sim 140$ $\mathrm{kb}$, which was subsequently named pQZ67 in this study.

\section{Analysis of the plasmid pQZ67}

The complete DNA sequence of plasmid pQZ67 was obtained by whole-genome sequencing (Fig. 4). 142,988-bp pQZ67 consisted of 38,000 amino acid residues and containing 185 potential edcoding sequences (CDSs), with a
$\mathrm{G}+\mathrm{C}$ content of $34.03 \%$. The vanRSHAX gene cluster was located between two insertion sequences which were IS21and IS256. It was a Tn1546-like compound transposon, which played a crucial role in horizontal transmission and might assist in the horizontal transfer of $v a n A$ in Enterococcaceae.

Multiple alignment showing the vanA-carrying fragments ( 13,780 bp) from the FSBM as well as Efm $4+$ $\mathrm{E} f s 2$ group were identical to the corresponding region of 
Table 2 Antimicrobial susceptibilities and sequence type of donor strain Efm4 and recipient strain Efs2

\begin{tabular}{|c|c|c|c|c|c|c|c|c|c|c|c|c|c|c|c|c|c|c|c|c|c|c|}
\hline \multirow[t]{2}{*}{ Strain } & \multirow[t]{2}{*}{ Origin } & \multicolumn{20}{|c|}{ Antibiotics } & \multirow[t]{2}{*}{ ST } \\
\hline & & VA & $\mathrm{TCL}$ & RA & C & AM & PIP & $C Z$ & P & MPN & AMX & OFL & $\mathrm{CIP}$ & GTF & GM & TE & MNO & $\mathrm{E}$ & KIA & FT & FU & \\
\hline Efm4 & FSBM & $\mathrm{R}$ & $\mathrm{R}$ & 1 & 1 & R & R & $\mathrm{R}$ & R & R & $\mathrm{R}$ & $\mathrm{R}$ & R & $\mathrm{R}$ & R & 1 & 1 & $\mathrm{R}$ & $\mathrm{R}$ & 1 & $\mathrm{R}$ & ST101 \\
\hline Efs2 & Feed additive & 1 & 1 & 1 & $R$ & 1 & 1 & 1 & 1 & 1 & 1 & $\mathrm{R}$ & R & I & $\mathrm{R}$ & $\mathrm{R}$ & 1 & $R$ & $R$ & 1 & 1 & ST69 \\
\hline
\end{tabular}

Efm, E. faecium isolates;

Efs, E. faecalis isolates;

\, susceptible;

$\mathrm{R}$, resistant;

I, intermediate;

ST, sequence type

VA, Vacomycin; TCL, Teicoplanin; RA, Rifampicin; C, Chloramphenicol; AM, Ampicillin; PIP, Piperacillin; CZ, Cefamedin; P, Penicillin; MPN, Meropenem; AMX, Amoxicillin; OFL, Ofloxacin; CIP, Ciprofloxacin; GTF, Gatifloxacin; GM, Gentamicin; TE, Tetracycline; MNO,

Minocycline; E, Erythromycin; Gl, Kitasamycin; FT, Nitrofurantoin; FU, Furazolidone

vanA-carrying plasmid in Efm4, expect single base mutation within vanA gene in transconjugants (Additional file 2: Supplemental data 1).

\section{Discussion}

To the best of our knowledge, this is the first time of the observation on the transfer of $v a n A$ of probiotic origin occurred in the process of FSBM and in the digestive tract of growing pigs. Over the past few decades, with the extensive emergence of antibiotic-resistant strains, probiotics are increasingly used in human and food animals as suitable replacements of antibiotics [33, 34]. As traditional lactic acid bacteria, E. faecium and E. faecalis have been wildly used in foods, drugs, dietary supplements, microbial feed and feed additives [35]. However, some prospective studies showed that these bacteria can serve as an accumulator of antibiotic resistance genes (ARGs) potentially providing them to pathogens, raising the problem of pathogen resistance [36, 37]. For the past two decades, the production and consumption of microbial products associated with the increase in intensive livestock farming, and the safety of these products is important for food safety. Previous studies have shown concern on probiotics applied in feed containing transferable ARGs [38, 39]. Using filter mating experiments, Nawaz et al. [40] found that ermB and tetM from lactobacillus strains could be successfully transferred to $E$. faecalis, with conjugation frequency ranged from $10^{-5}$ to $10^{-6}$. Moreover, Ma et al. [41] used Lactobacillus delbrueckii strain harboring $m c r C$ as donor strain, and $E$. faecalis ATCC 29212 as recipient strain, resulting in a conjugation frequency as high as $2.2 \times 10^{-2}$. Similarly, our study found out that, during the production of FSBM, the vanA could be transferred easily at the early stage (detected only $1 \mathrm{~h}$ after the fermentation began), and the transconjungations increased steadily during the whole fermentation process of FSBM. Nevertheless, the conjugation frequency ranged from $\sim 10^{-3}$ to $\sim 10^{-4}$, which was about 10 to 100 fold higher than primary studies [42, 43]. It might be because that FSBM provided a suitable environment for conjugations to happen, where three necessary conditions were need: full contact, absolute stationary and sufficient nutrition [44, 45].

Most of the previous experiments of resistance genes transfer in vivo were performed on specific pathogen

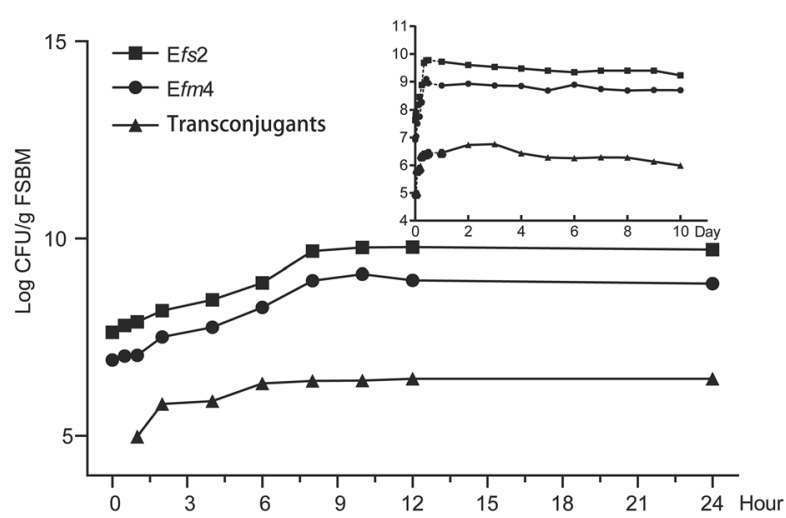

Fig. 1 Growth kinetics of Efm4, Efs2 and transconjugants during the fermentation process of soybean meal. The solid circular represents the growth kinetics of the donor strain Efm4. The solid square represents the growth kinetics of the donor strain Efm4; the solid minute triangle represents the growth kinetics of the transconjugants. Efm4, vanA positive strain Enterococcus faecium Efm4; Efs2, chloramphenicol-resistant strain Enterococcus faecalis Efs2 


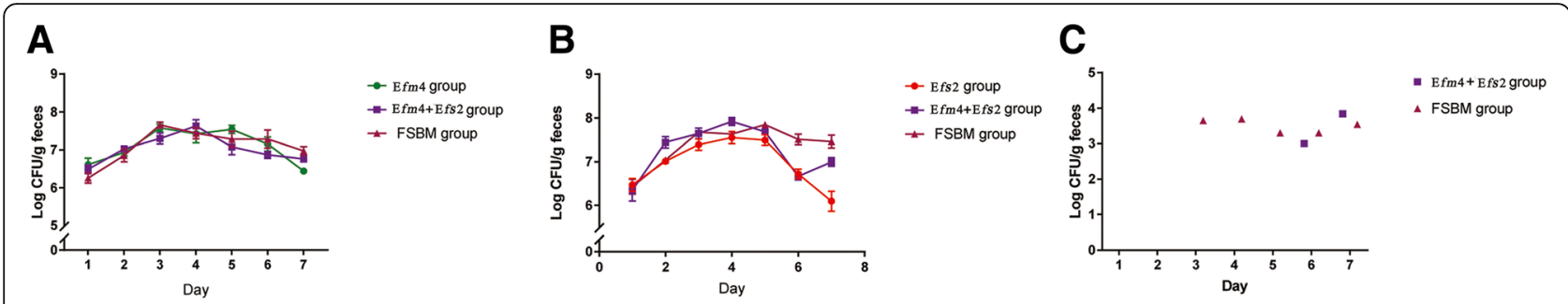

Fig. 2 Viable count of Efm4, Efs2 and transconjugants in feceal samples of growing pigs. (a): The growth kinetics of donor strain Efm4 in Efm4 group, Efm4+ Efs2 group and FSBM group; (b): The growth kinetics of receiver strain Efs2 in Efs2 group, Efm4+ Efs2 group and FSBM group; (c): The growth kinetics of transconjugants in Efm4+ Efs2 group and FSBM group. In both Efm4+ Efs2 group and FSBM group, the transconjugants were only detected in one pig out of six. Results from fecal samples obtained at $24 \mathrm{~h}$ before the experiment are plotted as day zero. FSBM, fermented soybean meal; Efm4, vanA positive strain Enterococcus faecium Efm4; Efs2, chloramphenicol-resistant strain Enterococcus faecalis Efs2

free (SPF) or gnotobiotic animals. Bourgeois- Nicolaos et al. [46] revealed that vanA could transfer from pig derived E. faecium to human derived $E$. faecalis in germ-free mice intestines, but only 2 colonies of transconjugants were detected after administration donor and receiver strains intragastrically for $14 \mathrm{~d}$. Moreover, the transfer of vanA-harboring plasmid from poultry and pig derived strain to human fecal E. faecium strains in digestive tract of germ-free mice was observed by Dahl et al. [47], indicating that even transient colonization strains might provide a significant reservoir to transfer resistance genes to permanent commensal bacteria. A study by Lester et al. [48] demonstrated that conjugation could occur in the human gastrointestinal tract. In this study, three of six volunteers who ingested $\sim 10^{9} \mathrm{CFU}$ vanA-harboring $E$. faecium bacteria in $250 \mathrm{~mL}$ milk had transconjugant bacteria in their feces at a mean conjugation frequency of $\sim 10^{-7}$ transconjugants / recipient. This was in line with the observations in our results, in particular for the $\mathrm{E} f m 4+\mathrm{E} f s 2$ group, as the

Table 3 Colony count of Efs2 and transconjugants from fecal samples of in vivo conjugation

\begin{tabular}{|c|c|c|c|c|c|c|c|c|c|c|c|c|c|}
\hline \multicolumn{2}{|c|}{ Day } & \multicolumn{6}{|c|}{$\mathrm{Efs} 2, \times 10^{6} \mathrm{CFU} / \mathrm{g}$ fecal } & \multicolumn{6}{|c|}{ Transconjugants, $\times 10^{3} \mathrm{CFU} / \mathrm{g}$ fecal } \\
\hline 1 & Efs2 & 7.60 & 1.50 & 0.80 & 4.50 & 4.90 & 3.30 & & & & & & \\
\hline & $\mathrm{Efm} 4+\mathrm{Efs} 2$ & 3.70 & 0.20 & 7.50 & 8.70 & 1.10 & 2.30 & 0 & 0 & 0 & 0 & 0 & 0 \\
\hline & FSBM & 0.55 & 2.85 & 4.90 & 5.50 & 1.35 & 6.50 & 0 & 0 & 0 & 0 & 0 & 0 \\
\hline \multirow[t]{3}{*}{2} & Efs2 & 12.50 & 8.20 & 17.50 & 8.85 & 11.25 & 6.30 & & & & & & \\
\hline & $\mathrm{Efm} 4+\mathrm{E} f s 2$ & 15.00 & 16.50 & 27.00 & 14.50 & 55.00 & 86.00 & 0 & 0 & 0 & 0 & 0 & 0 \\
\hline & FSBM & 12.30 & 15.00 & 11.30 & 12.50 & 7.50 & 8.50 & 0 & 0 & 0 & 0 & 0 & 0 \\
\hline \multirow[t]{3}{*}{3} & Efs2 & 22.50 & 8.50 & 13.50 & 55.00 & 36.00 & 42.00 & & & & & & \\
\hline & $\mathrm{E} f m 4+\mathrm{E} f s 2$ & 33.00 & 42.00 & 47.50 & 14.50 & 73.00 & 107.00 & 0 & 0 & 0 & 0 & 0 & 0 \\
\hline & FSBM & 41.00 & 47.5 & 36.00 & 46.00 & 58.00 & 59.50 & 0 & 0 & 0 & 4.50 & 0 & 0 \\
\hline \multirow[t]{3}{*}{4} & Efs2 & 68.00 & 77.00 & 34.50 & 55.50 & 36.00 & 57.00 & & & & & & \\
\hline & $\mathrm{E} f m 4+\mathrm{E} f s 2$ & 175.00 & 88.00 & 114.00 & 39.50 & 55.00 & 85.00 & 0 & 0 & 0 & 0 & 0 & 0 \\
\hline & FSBM & 20.50 & 19.00 & 21.00 & 6.00 & 12.20 & 3.50 & 0 & 0 & 0 & 5.00 & 0 & 0 \\
\hline \multirow[t]{3}{*}{5} & Efs2 & 55.00 & 101.5 & 23.00 & 27.00 & 72.00 & 36.00 & & & & & & \\
\hline & $\mathrm{Efm} 4+\mathrm{E} f s 2$ & 65.00 & 51.00 & 41.00 & 35.5 & 65.00 & 4.00 & 0 & 0 & 0 & 0 & 0 & 0 \\
\hline & FSBM & 43.00 & 65.00 & 87.00 & 95.00 & 86.5 & 60.00 & 0 & 0 & 0 & 2.00 & 0 & 0 \\
\hline \multirow[t]{3}{*}{6} & Efs2 & 3.50 & 1.85 & 5.30 & 9.40 & 7.80 & 8.30 & & & & & & \\
\hline & $\mathrm{Efm} 4+\mathrm{Efs} 2$ & 3.75 & 5.80 & 9.50 & 4.60 & 4.50 & 2.30 & 0 & 1.00 & 0 & 0 & 0 & 0 \\
\hline & FSBM & 55.00 & 18.00 & 14.00 & 34.00 & 27.00 & 92.00 & 0 & 0 & 0 & 2.00 & 0 & 0 \\
\hline \multirow[t]{3}{*}{7} & Efs2 & 6.55 & 7.80 & 1.55 & 1.80 & 3.80 & 6.75 & & & & & & \\
\hline & $E f m 4+E f s 2$ & 6.70 & 12.10 & 18.50 & 5.50 & 18.50 & 6.00 & 0 & 7.00 & 0 & 0 & 0 & 0 \\
\hline & FSBM & 10.00 & 12.00 & 27.0 & 46.50 & 84.00 & 45.00 & 0 & 0 & 0 & 3.50 & 0 & 0 \\
\hline
\end{tabular}

$\mathrm{Efm}, \mathrm{E}$. faecium isolates;

$E f s, E$. faecalis isolates;

FSBM, fermented soybean meal 


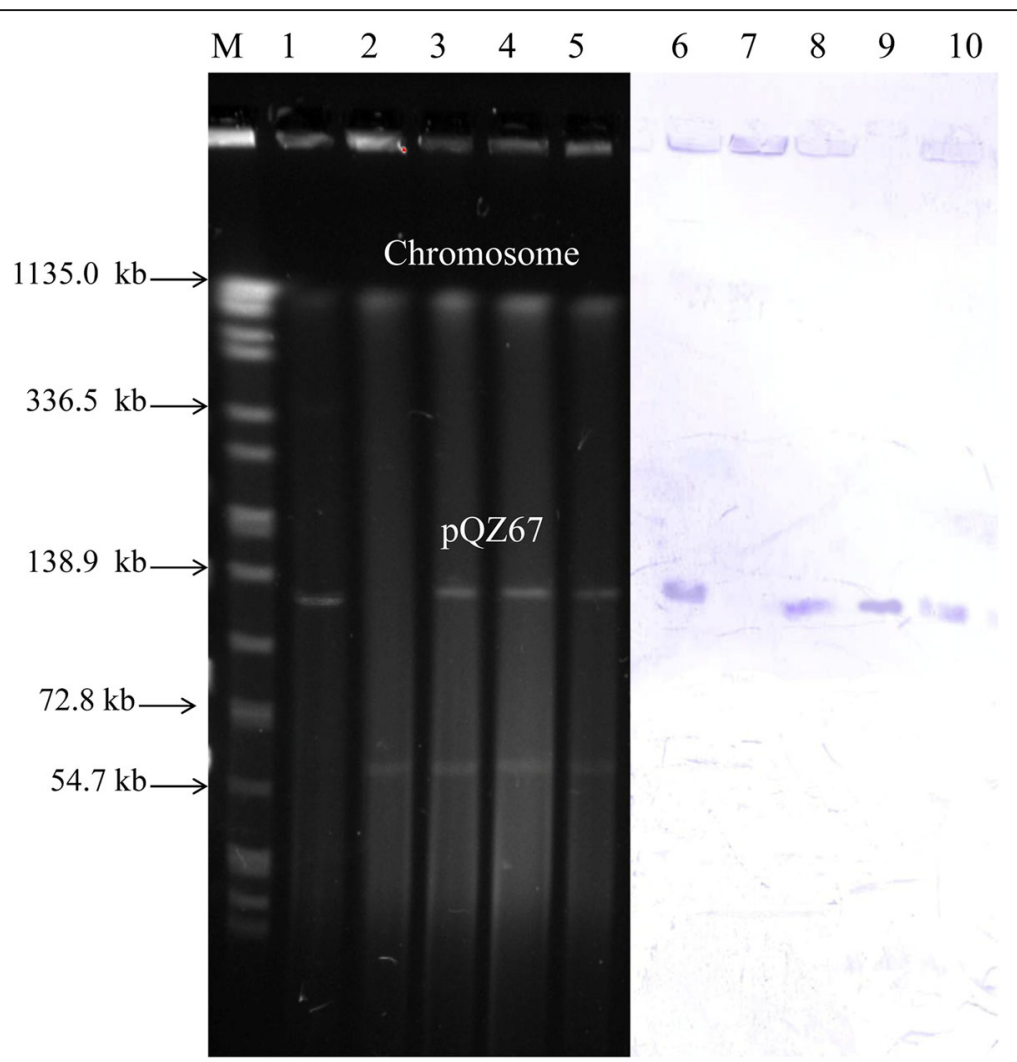

Fig. 3 S1-PFGE analysis of Efm4, Efs2 and transconjutions and southern hybridization. Line M, molecular weight marker Salmonella braenderup H9812; Line 1 and 6, donor strain E. faecium Efm4; Line 2 and 7, recipient strain E. faecalis Efs2; Line 3 and 8, transconjugants obtained from FSBM; Line 4 and 9, transconjugants obtained from Efm4+ Efs2 group; Line 5 and 10, transconjugants obtained from FSBM group. FSBM, fermented soybean meal; PFGE, pulsed-field gel electrophoresis; Efm4, vanA positive strain Enterococcus faecium Efm4; Efs2, chloramphenicol-resistant strain Enterococcus faecalis Efs2

transconjugants were obtained $5 \mathrm{~d}$ after ingesting $\mathrm{E} f m 4$ together with $\mathrm{E} f s 2$, and the conjugation frequency was $\sim 10^{-4}$ to $\sim 10^{-5}$.

It was noteworthy that transconjugants in the FSBM passed through the digestive tract of growing pigs successfully and could be detected after $3 \mathrm{~d}$ of feeding. Moreover, this cycle was $2 \mathrm{~d}$ sooner than feeding Efm4 and $\mathrm{E} f s 2$ directly. In addition, in commercial production facility, the SBM fermentation process usually lasted only for 2 to $5 \mathrm{~d}$ before further processing, and the inoculation amount of bacteria was much more than we used in the current study [49]. This emphasized the possibility that the resistance genes harbored by commercial probiotics used in feed and feed additives can be disseminated in digestive tracts of animal, which may cause further infections under extreme conditions.

Many researchers explored the transferability of resistance genes from farm to fork [50, 51]. Nawaz et al. [40] analyzed the antibiotic resistance in lactic acid bacteria from retail fermented foods in Xi'an, China. Not only did they identify tetS gene from Lactobacillus brevis and Lactobacillus kefiri for the first time, but they also observe the ermB gene from L. fermentum and L. salivarius. Furthermore, the tetM gene from L. plantarum and $L$. brevis was also observed to be successfully transferred to E. faecalis by filter mating, with a conjugation frequency as $\sim 10^{-6}$ to $\sim 10^{-5}$. In addition, He et al. [52] analyzed the oxazolidinone / phenicol resistance gene optrA from 17 non-related E. faecalis isolates from human and animal origin, and the IS1216E elements on the plasmid were also found to contribute the most in the dissemination of the optrA gene. The IS $1216 \mathrm{E}$ elements were also detected on pQZ67 plasmid in our study, demonstrating the likelihood of in vitro and in vivo transfer of vanA between enterococci and other Gram-positive bacteria from food or feed to animal or human via food chain in vitro and in vivo.

In this study, the diversity of STs showed that the commercial probiotic enterococci strains were from multiple sources. Additionally, it should be noted that the sequence type of VRE strain Efm4 was ST1014 (Fig. 3). ST1014 was evolved out of ST78, which was the dominant clone complex (CC) in most cities in China, causing the prevalence and spread of VRE [53]. 


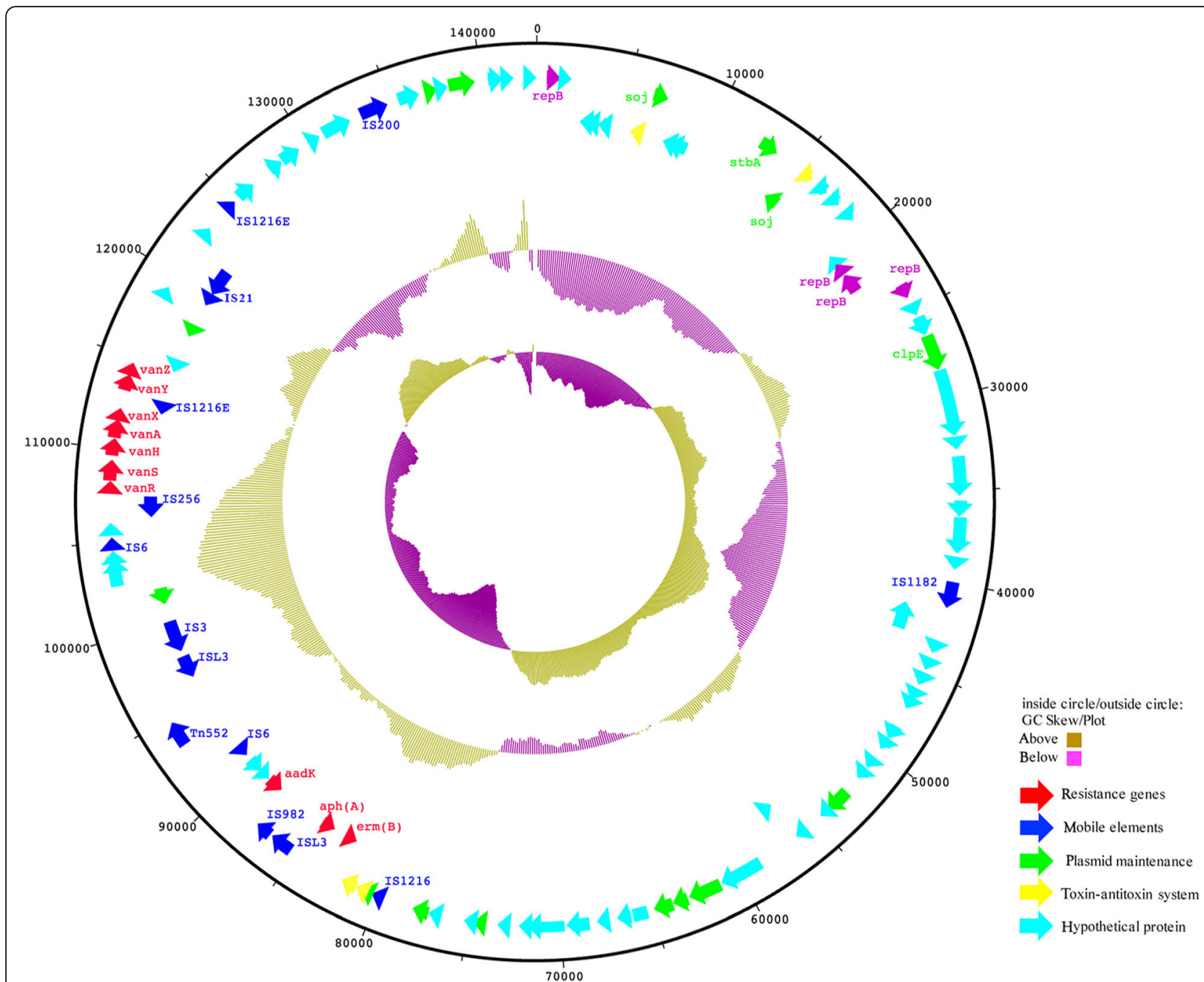

Fig. 4 Genetic map of the vanA harboring plasmid pQZ67. The circles display (from the outside to inside): (i) size in bp; (ii) positions of the predicted coding sequences transcribed in clockwise orientation; (iii) position of predicted coding sequences transcribed in counterclockwise orientation; (iv) GC content plotted against 50\%, with brown indicating $>50 \%$ and purple indicating $<50 \%$; and $(\mathbf{v}) \mathrm{GC}$ skew $[(\mathrm{G}+\mathrm{C}) /(\mathrm{G}-\mathrm{C})]$ in a window of $300 \mathrm{bp}$

Furthermore, another reported vancomycin resistant $E$. faecium strain with the same ST1014 was isolated in a hospital in Shandong Province, China, in 2013 [53]. Although there was no evidence showing the direct link between that isolate and $\mathrm{E} f \mathrm{~m} 4$, the possible affiliation between ST1014 and ST78 (CC17) still rang the alarms of the safety of probiotic enterococci applied in feed and food.

Ideally, probiotics used in food and feed production should harbor none of the transferable resistance genes and should be sensitive to pathogen related antibiotics [54]. European Food Safety Authority (EFSA) recommended that bacterial strains harboring virulence factors or transferable ARGs should not be used in animal feeds, probiotic and fermented foods for human $[55,56]$. The transmission of ARGs in digestive tracts is a major health concern related to the probiotic application. Unfortunately, until now, ARGs are not included in the standard screening assays before production and application in foods and feeds. Most of the fermentation starter probiotic strains that used for food and animal feed processing were lacking of thorough and rigorous assessments. The donor strain $\mathrm{E} f m 4$ used in this study was isolated from a retail FSBM product, revealing the risk of dissemination multiple resistant plasmids was not only through the ingestion of food animals, but also via further feed processing like SBM fermentation. In addition to vanA, the macrolide-resistant gene erm and two aminoglycoside resistant genes $a a d K$ and aphA were also identified in pQZ67 (Fig. 4), explained the resistant of Efm4 to erythromycin, kitasamycin and gentamicin. This also indicated that pQZ67 was a multidrug resistance plasmid. 
In the past decade, the consumption of FSBM in Asian countries has increased sharply accompanied with the rapid development of animal husbandry [57]. To date, although there has been no report of VRE or other antibiotic-resistance probiotics in FSBM and in the intestines of growing pigs, the potential risk of horizontal transfer of resistance genes is still hanging in cliff, because the consumption is huge while the surveillance is lacked.

\section{Conclusion}

In conclusion, our study illustrated that vanA could successfully transfer among enterococci during the fermentation process of soybean meal and also in the digestive tract of growing pigs. Thus, it is suggested that when considering an Enterococcus strain as a starter for probiotics, each specific strain should be carefully evaluated to determine the presence of all known virulence factors.

\section{Additional files}

Additional file 1: Table S1. Primers used for PCR and DNA sequencing in this study and size of the PCR-targeted products. Table S2. Name, abbreviation and drug concentration of 20 antibiotics. (DOCX 19 kb)

Additional file 2: Primers used for partially sequencing of transconjugations and size of the PCR-targeted products. (DOCX $96 \mathrm{~kb}$ )

\section{Abbreviations}

ARGs: Antibiotic resistance genes; BEA: Bile Esculin Azide; BHI: Brain heart infusion; CC: Clonal Complex; Efm: Enterococcus faecium; Efs: Enterococcus faecalis; FSBM: Fermented soybean meal; MIC: Minimum inhibitory concentration; PCR: Polymerase chain reaction; PFGE: Pulsed-field gel electrophoresis; SBM: Soybean meal; VRE: Vancomycin-resistant enterococci

\section{Acknowledgements}

We are grateful to Dr. Yongzhi Yang and Dr. Yingbo Shen for their excellent technical assistance.

\section{Funding}

This study was funded by National Key Research and Development Program of China (Grant number 2016YFD0501308) and Agro-scientific Research in the Public Interest (Grant number 201403047).

\section{Availability of data and materials}

All data generated or analyzed during this study are included in this published article and its supplementary information files.

\section{Accession number(s)}

The sequence of the 142,988-bp sequence of the van-carrying plasmid pQZ67 has been deposited in the GenBank database under accession No.CP025427.

\section{Authors' contributions}

SQ: Designed the experiments; NL and HY: Performed the experiments; NL, $\mathrm{HY}$ and $\mathrm{HL}$ : Analyzed the data; NL: wrote the paper, which was edited by XM, CW and SQ; ZW, CHS: Contributed reagents and analysis tools. SQ: Resourced the project. All authors read and approved the final manuscript.

\section{Ethics approval and consent to participate}

All procedures used in experiments of our lab were performed in accordance with the China Agricultural University Animal Care and Use Committee guidelines (ID: SKLAB-B-2010-003).
Consent for publication

Not applicable.

\section{Competing interests}

The authors declare that they have no competing interests.

\section{Author details}

${ }^{1}$ State Key Laboratory of Animal Nutrition, College of Animal Science and Technology, China Agricultural University, Beijing 10093, China. ${ }^{2}$ Beijing Key Laboratory of Bio-feed Additives, China Agricultural University, Beijing 10093, China. ${ }^{3}$ National Center for Veterinary Drug Safety Evaluation, College of Veterinary Medicine, China Agricultural University, Beijing 100193, China.

Received: 6 December 2018 Accepted: 7 March 2019

Published online: 12 April 2019

\section{References}

1. Arias CA, Murray BE. The rise of the Enterococcus: beyond vancomycin resistance. Nat Rev Microbiol. 2012;10:266-78. https://doi.org/10.1038/nrmicro2761.

2. Liu Y. The dissemination mechanism of the multi-resistant gene cfr in Enterococcus spp. from animal origin. [dissertation/docter's thesis]. Beijing: Chinese Agricultural University; 2013.

3. Thacker PA. Alternatives to antibiotics as growth promoters for use in swine production: a review. J Anim Sci Biotechnol. 2014;4:35-46. https://doi.org/ 10.1186/2049-1891-4-35.

4. Mallo JJ, Rioperez J, Honrubia P. The addition of Enterococcus faecium to diet improves piglet's intestinal microbiota and performance. Livest Sci. 2010;133:176-8. https://doi.org/10.1016/j.livsci.2010.06.057.

5. Capcarova M, Hascik P, Kolesarova A, Kacaniova M, Mihok M, Pal G. The effect of selected microbial strains on internal milieu of broiler chickens after peroral administration. Res Vet Sci. 2010;91:132-7. https://doi.org/10. 1016/j.rvsc.2010.07.022

6. Wang Y, Lu WQ, Li DF, Liu XT, Wang HL, Niu S, et al. Energy and ileal digestible amino Acid concentrations for growing pigs and performance of weanling pigs fed fermented or conventional soybean meal. Asian Austral J Anim. 2014;27:706-16. https://doi.org/10.5713/ajas.2013.13612.

7. Sun P, Wang JQ, Jiang YM. Effects of Enterococcus faecium (SF68) on immune function in mice. Food Chem. 2010;123:63-8. https://doi.org/10. 1016/j.foodchem.2010.03.128.

8. Wang Y, Yang GR, Zhang GG. Effects of Enterococcus faecium on growth performance, intestinal flora and immune function of weaner piglets. Chinese J Ani Nutr. 2013;25:1069-76. https://doi.org/10.3969/j.issn.1006-267x.2013.05.023.

9. Kim YR, Kim EY, Choi SY, Hossain MT, Oh R, Heo WS, et al. Effect of a probiotic strain, Enterococcus faecium, on the immune responses of olive flounder (Paralichthys olivaceus). J Microbiol Biotechnol. 2010;22:526-9.

10. Sydnor ER, Perl T. M. Hospital epidemiology and infection control in acute care settings. Clin Microbiol Rev. 2011;24:141-73. https://doi.org/10.1128/CMR.00027-10.

11. Miller WR, Munita JM, Arias CA. Mechanisms of antibiotic resistance in enterococci. Expert Rev Anti Infect Ther. 2014;12:1221-36. https://doi.org/10. 1586/14787210.2014.956092.

12. Jahan M, Zhanel GG, Sparling R, Holley AR. Horizontal transfer of antibiotic resistance from Enterococcus faecium of fermented meat origin to clinical isolates of E. faecium and Enterococcus faecalis. Int J Food Microbiol. 2015; 199:78-85. https://doi.org/10.1016/j.jifoodmicro.2015.01.013.

13. Leclercq R, Derlot E, Duval J, Courvalin P. Plasmid mediated resistance to vancomycin and teicoplanin in Enterococcus faecium. N Engl J Med. 1988; 319:157-61. https://doi.org/10.1056/NEJM198807213190307.

14. Cetinkaya Y, Falk P, Mayhall CG. Vancomycin-resistant enterococci. Clin Microbiol Rev. 2000;13:686-707. https://doi.org/10.1128/CMR.13.4.686-707.2000.

15. Weigel LM, Clewell DB, Gill SR, Clark NC, McDougal LK, Flannagan SE, et al. Genetic analysis of a high-level vancomycin-resistant isolate of Staphylococcus aureus. Science. 2003;302:1569-71. https://doi.org/10.1126/ science.1090956.

16. Fremin BJ, Bhatt AS. Allied commensal forces against vancomycin-resistant enterococci. Cell Host Microbe. 2017;21:559-60. https://doi.org/10.1016/j. chom.2017.04.015

17. Chen $\mathrm{CH}$, Sun JY, Guo Y, Lin DF, Guo QL, Hu FP, et al. High prevalence of vanM in vancomycin-resistant Enterococcus faecium isolates from Shanghai, China. Antimicrob Agents Chemother. 2015:59:7795-802. https://doi.org/10. 1128/AAC.01732-15 
18. Hammerum AM, Baig S, Kamel Y, Roer L, Pinholt M, Gumpert H, et al. Emergence of vanA Enterococcus faecium in Denmark, 2005-15. J Antimicrob Chemother. 2017;72:2184-90. https://doi.org/10.1093/jac/dkx138.

19. European Centre for Disease Prevention and Control (ECDC). Data from: Summary of the Latest Data on Antibiotic Resistance in the European Union. (2016). https://ecdc.europa.eu/en/publications-data/summary-latestdata-antibiotic-resistance-eu-2016

20. Klare I, Heier H, Claus H, Reissbrodt R, Witte W. VanA-mediated high-level glycopeptide resistance in Enterococcus faecium from animal husbandry. Fems Microbiol Lett. 1995;125:165-171. doi: 0378-1097(94)00493-5.

21. Ubeda C, Taur Y, Jenq RR, Equinda MJ, Son T, Samstein M, et al. Vancomycin resistant Enterococcus domination of intestinal microbiota is enabled by antibiotic treatment in mice and precedes bloodstream invasion in humans. J Clin Invest. 2010;120:4332-41. https://doi.org/10.1172/JCl43918.

22. Clinical and Laboratory Standards Institute. Methods for dilution antimicrobial susceptibility tests for bacteria that grow aerobically. 27th ed; 2015.

23. Raghavendra GA, Felicia G, Shi XR, Jose S, Sanjeev KN, Mike DT, et al. Antimicrobial resistance of Enterococcus faecium strains isolated from commercialprobiotic products used in cattle and swine. J Anim Sci. 2018;96: 912-20. https://doi.org/10.1093/jas/sky056.

24. Wang Y, Liu XT, Wang HL, Li DF, Piao XS, Lu WQ. Optimization of processing conditions for solid-state fermented soybean meal and its effects on growth performance and nutrient digestibility of weanling pigs. Livest Sci. 2014;5:697-702. https://doi.org/10.1016/j.livsci.2014.07.020.

25. Yang GH, Guan JJ, Wang JS, Jia F. Optimization of multi-strain solid state fermentation to improve the content of soybean meal protein by response surface analysis. Adv Mater Res. 2013;3:1224-1228. https://doi.org/10.4028/ www.scientific.net/AMR.690-693.1234.

26. Roberts MC, No DB, Marzluff JM, Delap JH, Turner R. Vancomycin resistant Enterococcus spp. from crows and their environment in metropolitan Washington State, USA: Is there a correlation between VRE positive crows and the environment? Vet Mic. 2016;194:48-54. https://doi.org/10.1016/j.vetmic.2016.01.022.

27. Kim M, Kwon TH, Jung SM, Cho SH, Jin SY, Park NH, et al. Antibiotic resistance of bacteria isolated from the ilnternal organs of edible snow crabs. PLoS ONE. 2013:8:e70887. https://doi.org/10.1371/journal.pone.0070887.

28. Liu YY, Wang Y, Walsh TR, Yi LX, Zhang R, Spencer J, et al. Emergence of plasmid-mediated colistin resistance mechanism MCR-1 in animals and human beings in China: a microbiological and molecular biological study. Lancet Infect Dis. 2016;16:161-8. https://doi.org/10.1016/S14733099(15)00424-7.

29. General Administration of Quality Supervision, Inspection and Quarantine of the People's Republic of China and China National Standardization Management Committee. Laboratory animal—guideline for ethical review of animal welfare. GB/T 35892-2018.

30. Peng ZX, Wang W, Hu YJ, Li FQ. Development and optimization of rapid detection of Enterococcus spp. in retailed raw pork and environment samples. J Food Saf Food Qual. 2016;7:2240-6.

31. Florence D, Bruno P, Patrice C. Detection of the van alphabet and identification of enterococci and staphylococci at the species level by multiplex PCR. J Clin Microbiol. 2004;42:5857-60. https://doi.org/10.1128/ JCM.42.12.5857-5860.2004.

32. Treangen TJ, Sommer DD, Angly FE, Koren S, Mihai P. Next generation sequence assembly with AMOS. Curr Protoc Bioinformatics. 2011;33:Unit11.8. https://doi.org/10.1002/0471250953.bi1108s33.

33. Quigley EM, Quera R. Small intestinal bacterial overgrowth: roles of antibiotics, prebiotics, and probiotics. Gastroenterology. 2006;130:78-90. https://doi.org/10.1053/j.gastro.2005.11.046.

34. Angelakis E, Merhej $V$, Raoult D. Related actions of probiotics and antibiotics on gut microbiota and weight modification. Lancet Infect Dis. 2013;13:88999. https://doi.org/10.1016/S1473-3099(13)70179-8.

35. Silbergeld EK, Graham J, Lance B. Industrial food animal production, antimicrobial resistance, and human health. Annu Rev Publ. Health. 2008;29: 151-69. https://doi.org/10.1146/annurev.publhealth.29.020907.090904.

36. Yoo SJ, Sung $\mathrm{H}$, Cho YU, Kim MN, Pai CH, Kim YS, et al. Role of horizontal transfer of the transposon $\operatorname{Tn} 1546$ in the nosocomial spread of vanA vancomycin-resistant enterococci at a tertiary care hospital in Korea. Infect. Control Hosp. Epidemiol. 2006;27:1081-7. https://doi.org/10.1086/507279.

37. Zhang QQ, Ying GG, Pan CG, Liu YS, Zhao JL. Comprehensive evaluation of antibiotics emission and fate in the river basins of China: source analysis, multimedia modeling, and linkage to bacterial resistance. Environ Sci. Technol. 2015;49:6772-82. https://doi.org/10.1021/acs.est.5b00729.
38. Robredo B, Singh KV, Baquero F, Murray BE, Torres C. Vancomycin- resistant enterococci isolated from animals and food. Int J Food Microbiol. 2000;54: 197-204. https://doi.org/10.1016/S0168-1605(99)00195-6.

39. Gousia P, Economou V, Bozidis P, Papadopoulou C. Vancomycin-resistance phenotypes, vancomycin-resistance genes, and resistance to antibiotics of enterococci isolated from food of animal origin. Food Borne Pathog Dis. 2015;12:214-33. https://doi.org/10.1089/fpd.2014.1832.

40. Nawaz M, Wang J, Zhou A, Ma C, Wu X, Moore JE, et al. Characterization and transfer of antibiotic resistance in lactic acid bacteria from fermented food products. Curr Microbiol. 2011;62:1081-9. https://doi.org/10.1007/ s00284-010-9856-2.

41. Ma X, Sun P, He PL, Han PF, Wang JJ, Qiao SY, et al. Development of monoclonal antibodies and a competitive ELISA detection method for glycinin, an allergen in soybean. Food Chem. 2010;121:546-51. https://doi. org/10.1016/j.foodchem.2009.12.045.

42. Niamh T, Declan B, Séamus F. Characterisation and transferability of antibiotic resistance genes from lactic acid bacteria isolated from lrish pork and beef abattoirs. Research in Microbiology. 2010;161:127-35. https://doi. org/10.1016/j.resmic.2009.12.010.

43. Conwell M, Daniels V, Naughton PJ, Dooley JSG. Interspecies transfer of vancomycin, erythromycin and tetracycline resistance among Enterococcus species recovered from agrarian sources. BMC Microbio. 2017:17:19-26. https://doi.org/10.1186/s12866-017-0928-3.

44. Werner G, Klare I, Witte W. Large conjugative vanA plasmids in vancomycinresistant Enterococcus faecium. J Clin Microbiol. 1999;37:2383-6.

45. Wiedenbeck J, Cohan FM. Origins of bacterial diversity through horizontal genetic transfer and adaptation to new ecological niches. FEMS MicrobiolRev. 2011;35:957-76. https://doi.org/10.1111/j.1574-6976.2011.00292.x.

46. Bourgeois-Nicolaos N, Moubareck C, Mangeney N, Butel MJ, DoucetPopulaire F. Comparative study of vanA gene transfer from Enterococcus faecium to Enterococcus faecalis and to Enterococcus faecium in the intestine of mice. FEMS Microbiol Lett. 2006;254:27-36. https://doi.org/10.1111/j.1574$6968.2005 .00004 x$

47. Dahl KH, Mater DD, Flores MJ, Johnsen PJ, Midtvedt T, Corthier G, et al. Transfer of plasmid and chromosomal glycopeptide resistance determinants occurs more readily in the digestive tract of mice than in vitro and exconjugants can persist stably in vivo in the absence of glycopeptide selection. J Antimicrob Chemother. 2007;59:478-86. https://doi.org/10.1093/jac/dkl530.

48. Lester $\mathrm{CH}$, Frimodt-Møller N, Sørensen TL, Monnet DL, Hammerum AM. In vivo transfer of the vanA resistance gene from an Enterococcus faecium isolate of animal origin to an E. faecium isolate of human origin in the intestines of human volunteers. Antimicriob. Agents Ch. 2006:50:596-600. https://doi.org/10.1128/AAC.50.2.596-599.2006.

49. Pangeni $D$, Jendza JA, Menon DR, Anil L, Yang X, Baidoo SK. Effect of replacing conventional soybean meal with low oligosaccharide soybean meal fed to weanling piglets. J Anim Sci. 2017:95:320-6. https://doi.org/10.2527/jas.2016.0780.

50. Verraes C, Boxstael SV, Meervenne EV, Coillie EV, Butaye P, Catry B, et al. Antimicrobial resistance in the food chain: A review. Int J Environ Res Public Health. 2013;10:2643-69.

51. Meervenne EV. Antibiotic resistance transfer during food production and preservation. [dissertation/docter's thesis]. Ghent: Ghent University.

52. He T, Shen Y, Schwarz S, Cai J, LV Y, Li J, et al. Genetic environment of the transferable oxazolidinone/phenicol resistance gene optrA in Enterococcus faecalis isolates of human and animal origin. J Antimicrob Chemother. 2016;71:1466-73.

53. Yan JG, Dong CZ, Zhao GM, Zhou WL, Sun X, Wang YL, et al. Drug resistance genes in vancomycin resistant Enterococcus faecium and MLST genotyping. Chin J Nosocomio. 2016;26:4092-7. https://doi.org/10.11816/cn. ni.2016-152595.

54. Founou LL, Founou RC, Essack SY. Antibiotic resistance in the food chain: A developing country perspective. Front Microbiol. 2016;7:1881-99.

55. European Food Safety Authority. Opinion of the scientific committee on a request from EFSA on the introduction of a qualified presumption of safety (QPS) approach for assessment of selected microorganisms referred to EFSA. EFSA J. 2007:187:1-16

56. European Food Safety Authority. Scientific opinion on the maintenance of the list of QPS biological agents intentionally added to food and feed. EFSA J. 2012;10:1-84

57. Zhang YT, Lu DD, Chen JY, Yu B, Liang JB, Mi JD, et al. Effects of fermented soybean meal on carbon and nitrogen metabolisms in large intestine of piglets. Animal. 2018;10:2056-64. 